\title{
Effect of Growth Retardant (CCC) and Growth Promoter (6-FAP) on Seedling Growth and Chlorophyll Content of Coleoptile Leaves in Pearl Millet (Pennisetum glaucum L.) Under Moisture Stress
}

\author{
Santosh Kumari* \\ Division of Plant Physiology, Indian Agricultural Research Institute, New Delhi, India \\ *Corresponding author
}

\author{
A B S T R A C T
}

\begin{abstract}
Keywords
Chlorophyll, Coleoptile, CCC, FAP, Growth, Polyethylene glycol, Radicle

Article Info

Accepted:

26 August 2017

Available Online:

10 September 2017

Cycocel ameliorated the osmotic stress at -4bar PEG by increasing chlorophyll contents in slow expanding shoots and increased radicle thickness enhancing root system under water stress. Remarkable effects of CCC on radicle thickness were displayed on root cap enlargement under -4 and -8 bars osmotic stress. Root growth/ radicle length was reduced drastically in kinetin treatments under all levels of water stress. Fast growing roots act as strong sink for food reserves and grow at the expense of shoot growth. The ability of cytokinins to establish local metabolic sinks in pre-soaked seed treatments could change the direction of assimilate transport and synthesis of auxin, gibberellin and ethylene in shoot and root meristems inverting the source-sink relationship in favour of shoot growth. Greater nitrogen productivity of seedlings emerging from protein rich pearl millet seeds presoaked in cytokinin may prove beneficial in increasing fodder yield under drought conditions. Cycocel treatment may have direct consequence on nutrient or water uptake and aboveground biomass/productivity under various levels of stresses.
\end{abstract}

\section{Introduction}

Growth retardants constitute one of the most important advances in agricultural technology. Inhibition of internode elongation, changes in the rates of development and effects on apical growth have been interpreted as indicating an effect of CCC on the endogenous gibberellin control system. These effects of growth retardant are reversible by gibberellin application and in this respect it is interesting to note that gibberellin treatments decreased the ability of the plants to survive under water stress (Sitinikova 1966). The growth retardants were not analogs of any known growth substances but they apparently gave a competitive interaction which was distinguishable from independent effects with the naturally occurring growth substances (Tolbert 1961). CCC has been considered as antimetabolites rather than an anti-gibberellins or anti-auxins (Lockhart, 1965) and appears to involve in an alteration in the metabolism of the plant such that it responds differently to a lowered water potential. Overexpression of Cytokinin oxidase/dehydrogenase enzyme coding gene result in slow growing stunted shoots with small leaves and enhanced root system of tobacco and Arabidopsis plants with reduced cytokinin contents (Werner et al., 2003, Yang et al., 2003). In view of profound changes in 
amino acid metabolism during water stress, it is of particular significance that $\mathrm{CCC}$ and cytokinins (6-FAP) have been shown to modify protein metabolism (Stoddart, 1965; Klyachka and Yakovleva, 1973). However, the mechanism of improved crop performance is unknown and no consistent response to growth regulators treatments during water stress has been found which can give conclusive results.

Pearl millet is the main source of calories of protein for the people who depend on it largely in arid and semi-arid areas where no other major cereal is adapted for cultivation. The ever present risk of drought in these areas makes grain yielding ability under drought conditions a major objective for pearl millet improvement programs. Progress in realizing the objective is limited by the general lack of methods to improve drought resistance in crop plants and by specific lack of knowledge of the responses to drought of millet crops itself. It is not clear if the adaptation of the crop to low average rainfall and a high degree of variability in annual amounts is due to specific (physiological) drought resistance mechanism or to a combination of short duration and heat tolerance. However, several developmental and morphological features are important in the ability to produce a crop in spite of recurrent stress and too little is known about the effect of growth retardant (CCC) and growth promoter (6-FAP i.e. kinetin) on seedling growth and establishment under moisture stress. Therefore, it was imperative to study effect of growth retardant (CCC) and growth promoter (6-FAP) on seedling growth and chlorophyll content of coleoptile leaves in pearl millet (Pennisetum glaucum L.) under moisture stress.

\section{Materials and Methods}

Germination studies were conducted on pearl millet under simulated drought conditions created by adding solutions of polyethylene glycol (PEG 6000 molecular weight) of different ranges of water potential viz., $0,-4$ and -8 bars prepared according to Michel and Kaufmann (1973). The seeds were surface sterilized by $80 \%$ methanol. These seeds were presoaked in $3.2 \mathrm{mM}$ and $6.4 \mathrm{mM}$ concentrations of Chloro Choline Chloride (CCC- cycocel); $0.025 \mathrm{mM}$ and $0.050 \mathrm{mM}$ concentrations of 6-Furfuryl Amino Purine (FAP-Kinetin; dissolved in $0.1 \mathrm{~N} \mathrm{NaOH}$ and final volume was made with distill water) for $4 \mathrm{~h}$ in each concentration. These 20 seeds were then subjected to germination in sterilized petri dishes $(9 \mathrm{~cm}$ diameter) lined with Whatman filter paper No.1, containing $10 \mathrm{ml}$ solutions of varying levels of water stress. The petri dishes were then put in polyethylene bag and placed in a lit incubator at $32^{\circ} \pm 2^{\circ} \mathrm{C}$. Three petri dishes were sampled for various growth parameters from each stress level, at periodic intervals viz. 72, 96 and 120 hours. Average for 30 seeds of pearl millet under each treatment was used for the analysis of length of radicle and coleoptile measured by ruler in $\mathrm{cm}$ per seedling and data has been presented as photographs of representative seedlings.

\section{Chlorophyll estimation}

$100 \mathrm{mg}$ of fresh coleoptile from each treatment was homogenized in $80 \%$ ethanol and centrifuged at 5,000 rpm for $15 \mathrm{~min}$. to extract chlorophyll and colorless residue was discarded. The O.D. was measured at $652 \mathrm{~nm}$ against $80 \%$ ethanol as blank using Beckman Spectrophotometer (Model B).

\section{Results and Discussion}

This study reveals that inhibition of the start of germination (McDonough, 1975) in sufficiently concentrated osmotic media and prevention of cell expansion involved in inhibition of radicle growth (Haber and 
Luippold 1960a) were completely removed by cycocel in vigorously germinating seeds under all levels of water stress. Root growth/ radicle length was reduced drastically in kinetin treatments under all levels of water stress. Cycocel remarkably increased the radicle growth under severe water stress $(-8$ bars PEG) when compared with all other treatments; ameliorating the inhibitory effect on shoot growth as well (Fig.1D; 1A, B, C).

Water soaked seed pretreatment (control) markedly increased the radicle/primary root length in comparison to untreated control, low concentration (0.025 mM FAP) and high concentration ( $0.050 \mathrm{mM}$ FAP) of kinetin and low concentration of Cycocel (3.2 mM CCC) under normal water availability (control) and water stress ( -4 and -8 bars of PEG- 6000) conditions (Fig.1B; 1A, E, F\&C).

Lateral root emergence from primary root of water presoaked and cytokinin treatments in pearl millet seedling are closely linked with shoot development/ photosynthesizing leaves (Fig.1B, E, F and 1A, C, D) than control and cycocel treatments. Kinetin stimulated leaf expansion and shoot growth was distinct in control and water stress of -4 bars. However, a diminishing supply of new cells was attributed for the reduction in root growth (Ross and Hegarty, 1980) and germination in lucerne seeds under water stress.

PEG induced water stress drastically reduced the chlorophyll contents in coleoptile leaves at all sampling hours (Fig.2A, B, C). Cycocel ameliorated the osmotic stress at -4bar PEG by increasing chlorophyll contents (Fig.2B) in slow expanding shoots and increased radicle thickness enhancing root system under water stress. Remarkable effects of CCC on radicle thickness were displayed on root cap enlargement under -4 and -8 bars osmotic stress. On the other hand, cytokinin induced cell division in root and shoot tissue (exhibited in extension growth) utilized amino acids, proteins and carbohydrates reserve of seeds in expansion activities and resulting in dilution of chlorophyll contents in coleoptile leaves.

Germination of seeds in various osmotic potentials, gave the test of a relative measure of any difference among varieties for their character of drought resistance. This consists of germination of seeds in various osmotic solutions and the assumption involved is that if a seed can germinate by absorbing water against a high osmotic gradient, the resulting plant could also absorb water better on account of its high osmotic pressure (Manohar and Heydecker, 1964). Some accept that the ability of germination in higher osmotic potential is inherent and correlated with drought resistance (Vasudevan and Balasubramanium, 1965). Stimulation of germination with growth regulators treatments under high temperature and humidity, high temperature and low water potential, and osmotic stress had been reported (Lyuberskaya and Likholat, 1981; Braun and Khan, 1976) but root growth was reduced by kinetin (Heydaker and Joshua, 1977) indicating separate control mechanism for subsequent radicle growth. The differential response of root and shoot to moisture stress was attributed to greater dependence of the root on the seed reserve food and less dependence on water uptake during the early non photosynthetic stage of seedling growth (Parmar and Moore, 1968).

The ability of cytokinins to establish local metabolic sinks at cytokinin treated areas i.e. plumule and radicle of embryo in pre-soaked seed treatments could change the direction of assimilate transport and synthesis of auxin, gibberellin and ethylene in shoot and root meristems inverting the source-sink relationship in favour of shoot growth (Kuiper, 1993; Sakakibara et al., 2006). 
Fig.1 Effect of growth retardant (CCC) and growth promoter (6-FAP) on radicle and coleoptiles growth and morphology in pearl millet (Pennisetum glaucum L.) under moisture stress; AControl; B- water pre-soaked; C - 3.2 mM CCC; D - 6.4 mM CCC; E - 0.025 mM FAP; F $0.050 \mathrm{mM}$ FAP

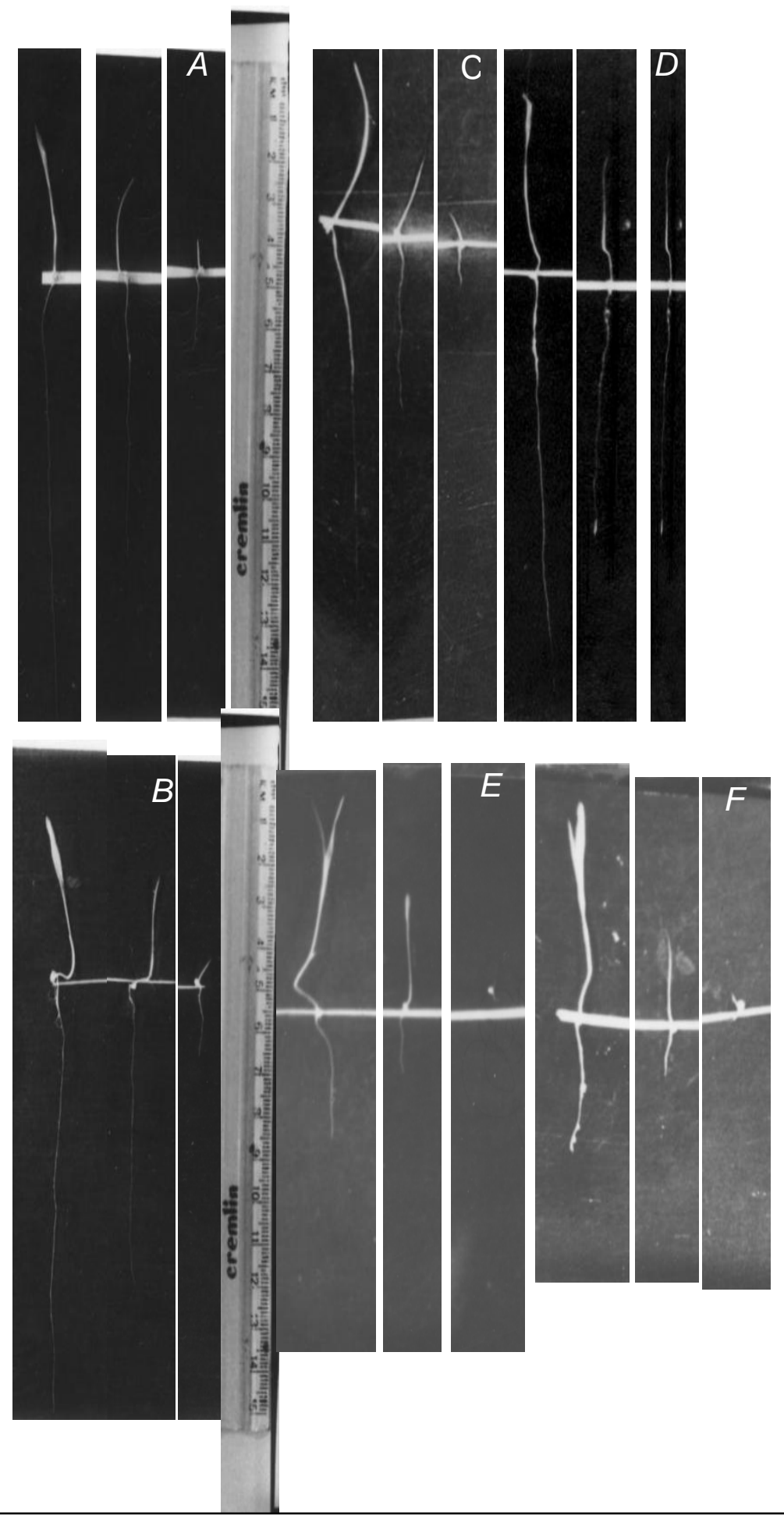

Water -4 bars -8 bars Water -4 bars -8 bars Water -4 bars -8 bars 
Fig.2 Effect of growth retardant (CCC) and growth promoter (6-FAP) on chlorophyll content of coleoptile leaves of pearl millet (Pennisetum glaucum L.) seedlings under moisture stress
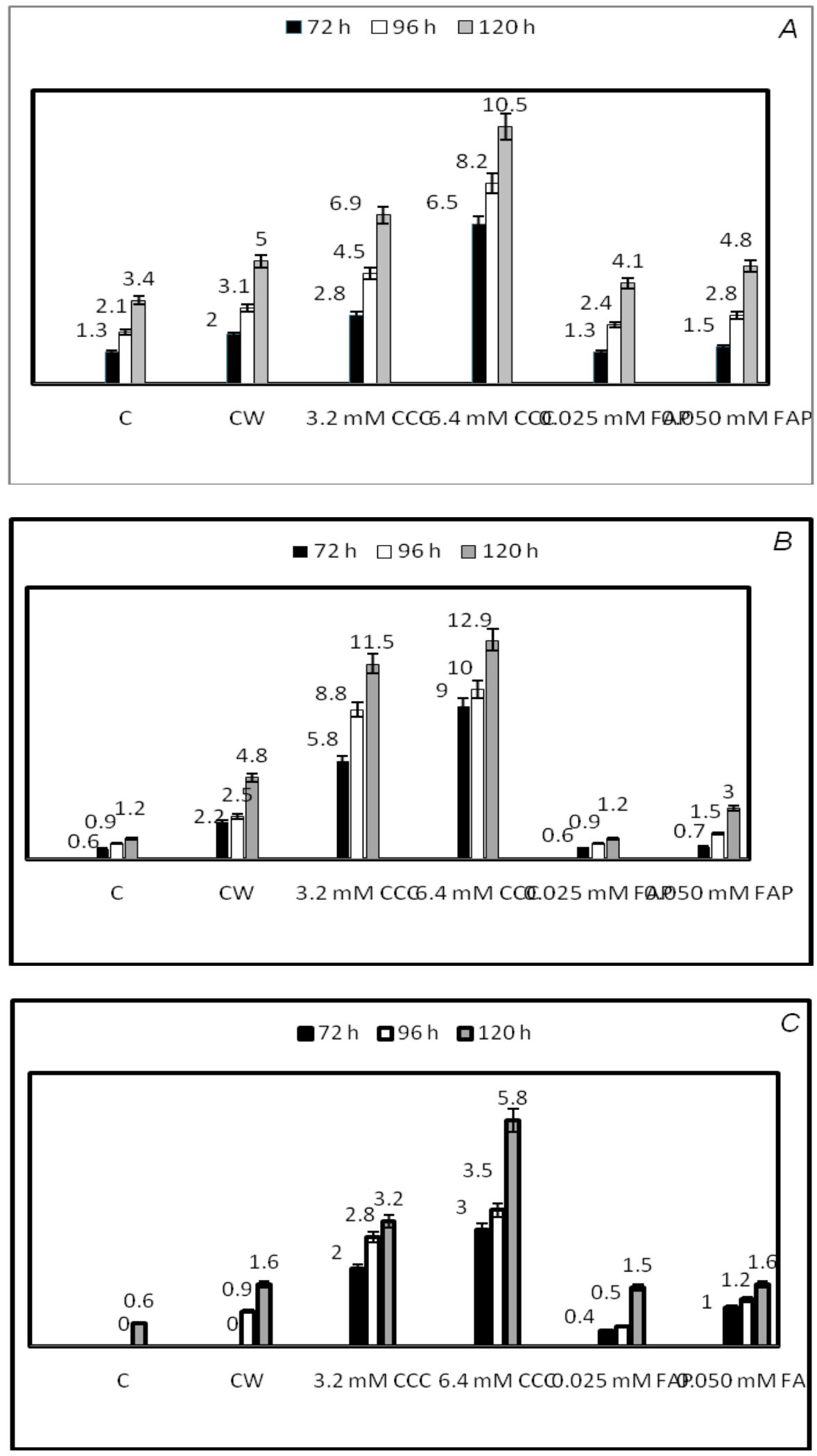
Fast growing roots act as strong sink for food reserves and grow at the expense of shoot growth. The rapid metabolic utilization of sugars and increased invertase activities have been reported (Werner et al., 2008) in fast growing roots in cytokinin deficient tobacco plants. The inhibition of invertase activity (Huber et al., 1974) under salinity stress and amylase, protease and invertase activities under water stress (Santosh Kumari, 1987) in growth regulator treated pearl millet leaves could partly explain the reduced root/radicle elongation. Therefore, reduced mobilization of seed reserves or assimilates accompanied with non-availability of water for cell expansion (Haber and Luippold (1960a) reduced seedling growth in all treatments under osmotic /water stress. Pre-soaking with water increased water contents of the seeds and helped to grow faster and had an edge over other treatments even under mild water stress ( -4 bars PEG). Faster shoot growth and mobilization of assimilates from leaves were reflected in lateral root emergence near shoot base.

Pearl millet genotype that can tolerate drought at early stage (3-15 days seedlings) had $30 \%$ more root length than susceptible one. Growth retardant CCC provides benefit under such conditions as displayed by root length under severe water stress/ osmotic stress ( -8 bars PEG). In grasses, thicker roots and high tissue density (Youssef and Abd El-Aal 2013) visible in CCC treatments especially under water stress have been associated with increased longevity and nutrient conservation in nutrient poor environment (Eissenstat and Yanai 1997).On the other hand shoot growth stimulation may reduce grain yield while increasing fodder yield in growth promoter (Kinetin) treated crop. CCC being hygroscopic quaternary ammoniums salt its catabolic product might provide nitrogen and increase water suction pressure of presoaked seeds. Elevated carbon dioxide favors investment of biomass in roots if nutrients cannot be absorbed in proportion to the $\mathrm{CO} 2$ enhanced growth. Therefore, CCC stimulated seed respiration may contribute in the primary root extension by the availability of carbon and nitrogen (high protein/nitrogen content in pearl millet seeds and reduced digestibility renders grains unsuitable for human health) under water stress. Increased root sink strength or relative allocation of photo assimilates to roots may govern the proliferation and extension of lateral roots (Erica et al., 2012) under normal and drought conditions in all presoaked treatments.

Root tips are the source of cytokinin production and their transport to the shoot is of prime importance in maintaining normal growth by a direct effect through interaction of auxin, gibberellin and ethylene (Gasper and Xhaufflaire, 1967; Dorimont, et al., 1971; Hemberg, 1972). Marked increase in root diameter was attributed to enlarged stele in sunflower (Farrahi and Scherifiah, 1973) under cytokinin treatments and cycocel treatments (Youssef and Abd El-Aal 2013). However, cytokinin treated seedlings displayed reduced radicle growth and chlorophyll contents due to reduced availability of water under osmotic stress. Cytokinin is known to influence chlorophyll content, biosynthesis and photosynthesis (Yaronskaya et al., 2006). However, in cytokinin deficient plants less chlorophyll was not limiting for photo assimilation and did not restrict shoot growth (Werner et al., 2008); cytokinin- mediated regulation of the sink strength differs between shoots and roots. Greater nitrogen productivity/shoot biomass (Poorter et al., 1990, Borman et al., 1991) of seedlings emerging from protein rich pearl millet seeds presoaked in cytokinin may consequently result in higher fodder yield under drought conditions. Cycocel treatment may have direct consequence on nutrient or water uptake and aboveground 
biomass/productivity under various levels of stresses.

Our analysis suggests the interaction of growth regulators in controlling root phenotypes and their impact on grain/fodder yield and drought tolerance in pearl millet.

\section{References}

Borman, M.M., Krueger, W.C. and Johnson, D.E. 1991. Effects of established perennial grasses on yields of associated annual weeds. J. Range Manage. 44:318-322.

Braun, J.W., and Khan, A.A. 1976. Alleviation of salinity, light and temperature stress by plant growth regulators permeated in lettuce seeds via acetone. J. Am. Soc. Hortic. Sci., 101: 716-721.

Doi: $10.1111 / \mathrm{nph} .12081$

Dorimont, E., Gasper, T.H. and Hofinger, M. 1971.Auxin-Kinetin interaction on lentil root growth in relation to indole acetic acid metabolism. Z. Pflanzenphysiol., 64: 232-240.

Eissenstat, D.M., and Yanai, R.D. 1997. The ecology of root lifespan. Adv. Ecol. Res., 27: 1-60.

Farrahi, A.S., and Scherifiah, S. 1973. The effect of Chlorocholine chloride (CCC) on the formation of root system of sunflower in relation to soil water content. Zietschroft Fur Pflanzen.und Boden, 602(1): 52-56.

Gasper, T.H., and Xhaufflaire, A. 1967. Effect of Kinetin on growth, auxin metabolism, peroxidase and catalase activities. Planta, 72: 252-257.

Hemberg, T., 1972. The effect of Kinetin on the occurrence of acid auxin in Coleus blumeii. Physiol. Plant., 26: 98-103.

Heydaker, W., and Joshua, A. 1977. Alleviation of thermo dormancy of lettuce (Lactuca sativa L.) seeds. J.
Hort. Sci., 52: 87-98.

Huber, W., Rustogi, P.N. and Sunkhla,N. 1974. Eco-Physiological studies on Indian arid zone plants. III. Effect of sodium chloride and gibberellin on the activity of the enzymes of carbohydrate metabolism in leaves of Pennisetum typhoides. Oecologia, 15: 77-86.

Klyachka, N.L., and Yakovleva, L.A. 1973. Activity of protein synthesizing system in isolated Gourd cotyledons in vivo and the effect of 6-Benzyl amino purine on it. Fiziol. Rast, 20(6): 1037-1041.

Kuiper, D., 1993. Sink strength: established and regulated by plant growth regulators. Plant cell Environ, 16: 10251026.

Lockhart, J.A., 1965. In Plant Biochemistry. Bonner, J. and Varner, J.C. (Eds.) pp.878 Acad. Press New York.

Lyuberskaya, N.C., and Likholat, T.V. 1981. Effect of cytokinin and gibberellin on germination of the seeds of aTriticum agropyronhybrid underunfavorable conditions. Fiziol. Rast, 28(4): 614-619.

Manohar, M.S., and Heydecker, W. 1964. Effects of water potential on germination of pea seeds. Nature, 202: 22-24.

Parmar, M.T., and Moore, R.P. 1968. Effect of simulated drought by polyethylene glycol solutions on corn (Zea mays L.) germination and seedling development. Agron. J., 58: 391-392.

Passot, S., Gnacho, F., Moukouanga, D., Lucas, M., Guyomarćh, S. et al., 2016. Characterization of pearl millet root architecture and anatomy reveals three types of lateral rots. Frontiers $\mathrm{Pl}$. sci., $7, \quad$ art.829. Doi: 10.3389/fpls.2016.00829

Poorter, H., Remkes, C. and Lambers, H.1990. Carbon and nitrogen economy of 24 wild species differing in relative growth rate. Pl. Physiol., 94:621-627.

Ross, H.A., and Hegarty, T.W. 1980. Action 
of growth regulators on lucerne germination and growth under water stress.New Phytol., 85: 495-501.

Sakakibara, H., Takei, K. and Hirose, N. 2006. Interactions between nitrogen and cytokinin in the regulation of metabolism and development. Trends Pl. Sci., 11: 440-448.

Santosh Kumari, 1987. Effect of growth regulators on growth and metabolism of bajra (Pennisetum typhoides L.) and sunflower (Helianthus annuus L.) under simulated drought conditions. Ph.D. Thesis, COBS\&H, HAU, Hissar, Haryana.

Sitinikova, O.A., 1966. Influence of growth regulators on the water metabolism of field beans. Soviet. Pl. Physiol., 13: 263-271.

Smithwick, E.A.H., Eissenstat, D.M., Lovett, G.M., Bowden, R.D., Rustad, L.E. and Driscoll, C.T. 2013. Root stress and nitrogen deposition: consequences and research priorities. New Phytol, 197(3): 712-719.

Stoddart, J.L., 1965. Chemical changes in Lolium temulentum $\mathrm{L}$. after treatment with (2-Chloroethyl) trimethyl ammonium chloride (CCC). J. Exp. Bot., 16: 604-613.

Tolbert, N.E., 1960. (2- Chloroethyl) trimethyl ammonium chloride and related compounds as plant growth substances. II. Effect on growth of wheat. Pl. Physiol. 35: 380-385.

Vasudevan, V., and Balasubramanium, V.1965. Germination in osmotic solutions as an index of drought resistance in sorghum. Madras Agric. J., 52: 386-390.

Werner, T., Holst, K., Pörs, Y., Guivarćh, A., Mustroph, A., Chriqui, D., Grimm, B. and Schmülling, T. 2008. Cytokinin deficiency causes distinct changes of sink and source parameters in tobacco shoots and roots. J. Exp. Bot., 59(10): 2659-2672.

Werner, T., Motyka, V., Laucou, V., Smets, R., Van Onckelen, H., Schmülling, T. 2003. Cytokinin- deficient transgenic Arabidopsis plants show multiple developmental alterations indicating opposite functions of cytokinins in the regulation of shoot and root meristem activity. Pl. Cell, 15: 2532- 2550.

Yang, S., Yu, H., Xu, Y., Goh, C.J. 2003. Investigation of cytokinin deficient phenotypes in Arabidopsis by ectopic expression of orchid DSCKXI. FEBS Letters, 555: 291-296.

Youssef, A.S.M., and Abd El Aal, M.M.M. 2013. Effect of paclobutrazol and cycocel on growth, flowering, chemical composition and histological features of potted Tabernaemontana coronaria Stapf plant. J. Appl. Sci. Res., 9(11): 5953-5963.

\section{How to cite this article:}

Santosh Kumari. 2017. Effect of Growth Retardant (CCC) and Growth Promoter (6-FAP) on Seedling Growth and Chlorophyll Content of Coleoptile Leaves in Pearl Millet (Pennisetum glaucum L.) Under Moisture Stress. Int.J.Curr.Microbiol.App.Sci. 6(9): 2522-2529. doi: https://doi.org/10.20546/ijcmas.2017.609.310 